\title{
High Resolution Decision Maps for Urban Planning: A Combined Analysis of Urban Flooding and Thermal Stress Potential In Asia and Europe
}

\author{
Floris Boogaard ${ }^{1,2^{*}}$, Zoran Vojinovic ${ }^{5}$, Yu-Cheng Chen $^{3}$, Jeroen Kluck ${ }^{2,4}$ Tzu-Ping Lin ${ }^{3}$ \\ ${ }^{1}$ Hanze University of Applied Sciences Groningen, Zernikeplein 7, P.O. Box 30030, Groningen, The \\ Netherlands \\ ${ }^{2}$ Tauw bv, PoBox 133, 7400 AC Deventer, The Netherlands \\ ${ }^{3}$ National Cheng Kung University, Daxue Rd, Tainan City, Taiwan 701, Taiwan \\ ${ }^{4}$ Amsterdam University of Applied Sciences, Weesperzijde 190, 1097 DZ Amsterdam, The \\ Netherlands \\ ${ }^{5}$ UNESCO-IHE, Westvest 7, 2611 AX Delft, The Netherlands.
}

\begin{abstract}
Urban flooding and thermal stress have become key issues for many cities around the world. With the continuing effects of climate change, these two issues will become more acute and will add to the serious problems already experienced in dense urban areas. Therefore, the sectors of public health and disaster management are in the need of tools that can assess the vulnerability to floods and thermal stress. The present paper deals with the combination of innovative tools to address this challenge. Three cities in different climatic regions with various urban contexts have been selected as the pilot areas to demonstrate these tools. These cities are Tainan (Taiwan), Ayutthaya (Thailand) and Groningen (Netherlands). For these cities, flood maps and heat stress maps were developed and used for the comparison analysis. The flood maps produced indicate vulnerable low-lying areas, whereas thermal stress maps indicate open, unshaded areas where high Physiological Equivalent Temperature (PET) values (thermal comfort) can be expected. The work to date indicates the potential of combining two different kinds of maps to identify and analyse the problem areas. These maps could be further improved and used by urban planners and other stakeholders to assess the resilience and well-being of cities. The work presented shows that the combined analysis of such maps also has a strong potential to be used for the analysis of other challenges in urban dense areas such as air and water pollution, immobility and noise disturbance.
\end{abstract}

\section{Introduction}

Stormwater flooding and thermal stress have become two very important issues for most urbanised areas. Municipalities and authorities in charge of water management, urban

\footnotetext{
*Corresponding author: Floris@noorderruimte.nl
} 
planning and building construction need insight into the risks of the storm water flooding and thermal stress. This is required in order to develop cost effective mitigating measures, preferably at a street or even house level.

Due to the climate change, the two issues of flooding and thermal stress are expected to increase in frequency and impact in the near future, especially for dense urban areas. For example, increasing temperatures are resulting in higher urban heat stress causing cities to be unpleasant and unhealthy places to live and work. Extreme heat waves ultimately result in a significant increase in the urban mortality rate due to heat stress [1].

It is therefore essential that public health and disaster management sectors adequately assess the vulnerability to stormwater flooding and thermal stress. Since both issues are expected to involve similar measures in the urban planning and design, it is logical to try to analyse and solve these issues simultaneously. The interaction of the two issues therefore needs to be further investigated.

To achieve this goal, three cities in different climate regions with varying urban contexts were selected as pilot areas; Tainan in Taiwan, Ayutthaya in Thailand and Groningen in The Netherlands. Maps of stormwater flooding and thermal stress for those case studies have been compared in this study.

\section{Method}

\subsection{Study areas}

Tainan is a highly developed city $\left(22^{\circ} 59^{\prime} \mathrm{N}, 120^{\circ} 11^{\prime} \mathrm{E}\right)$ in the tropical south of Taiwan. The total area of Tainan is $175.6 \mathrm{~km}^{2}$, including 6 administrative districts and a population of almost 2 milion people. Groningen $\left(53^{\circ} 13^{\prime} \mathrm{N}, 6^{\circ} 34^{\prime} \mathrm{E}\right)$ has a population just over of 200.000. It is the largest city in the north of the Netherlands with total area of $83.69 \mathrm{~km}^{2}$. Ayutthaya city $\left(14^{\circ} 21^{\prime} \mathrm{N}, 100^{\circ} 35^{\prime} \mathrm{E}\right)$ covers an area of $14.84 \mathrm{~km}^{2}$ with a population around 70.000 .

Fig. 1 shows the average rainfall andtemperature of Tainan and Groningen. The comparisons show that the average temperature of each month varies between $18-30^{\circ} \mathrm{C}$ in Tainan, and between $2-16^{\circ} \mathrm{C}$ in Groningen. Concerning the precipitation, Tainan has the largest rainfall during June to August due to the typhoon season. The monthly rainfall in Groningen is lower than the peak in Tainan, and is more constant over the year. Ayutthaya has a tropical monsoon climate and the highest average temperature of any city in the world. Temperatures in Ayutthaya regularly remain well above $30^{\circ} \mathrm{C}$ throughout the year. The humidity levels are also high during this period and you can expect short spells of rainy weather, with frequent afternoon showers and occasional thunderstorms and monsoons [2].
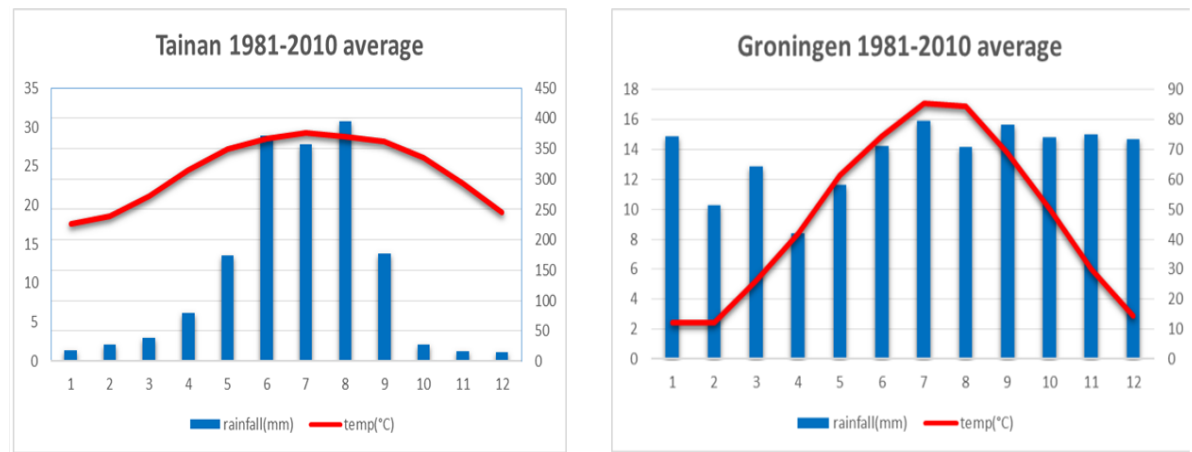

Fig. 1 Climate data in Tainan and Groningen 


\subsection{Basic information collection}

The basis for the flood modelling in the Groningen case is an accurate DEM (Digital Elevation Model) of the urban area with a high resolution (4 points $\left./ \mathrm{m}^{2}\right)$, maps of pervious and impervious surfaces and surface water. In addition, the heat stresss maps use information of land use including aerial photographs that allow green areas and trees to be mapped.

For Tainan an accurate DEM is unfortunately not available. Therefor a low resolution DEM (30 m resolution) was used in this study, validated by mobile field measured elevation data. The basic urban development information to estimate thermal stress potential was collected from the government and included the land use, population density, total floor area and height of building. The meteorological data in Tainan were derived from the central weather bureau. These data were used to set up the initial conditions for thermal stress calculation, and further make the verification of simulation results. In the case of Ayutthaya (Thailand), a DEM with $20 \mathrm{~m}$ resolution was applied. [3].

\subsection{Spatial resolution of the mapping}

The spatial resolution for the three cases differ greatly. This difference is due to the fact that a compromise had to be made between the size of the study area, the spatial resolution and the accuracy of modeling. In general, the larger the study area the simpler or less accurate the quick scan models need to be (physical simplifications and coarser resolutions) because of computational limitations. The continued improvement of the computational capabilities of computers and DEMs with high resolutions means it is now possible to make more accurate models with high resolutions. However to keep computational times limited, it is best to simplify the modeling of the physical processes. Comparing the results of the quickscan assessments with results of more complete and more accurate models (for a limited area) shows that if the quick scans have sufficient detail they give valuable results.

\subsection{Flood mapping}

For the flood map analysis in Groningen, the Calamity Levels of Urban Drainage Systems (CLOUDS) was used. This is 'quick-scan' method to simulate storm water floodings [4]. CLOUDS is based on the assumption that for a cloud burst $(>60 \mathrm{~mm} / \mathrm{h}$ ) most of the stormwater will flow and stay above ground. CLOUDS visualizes the streamlines and the depth of stormwater in depressions where water will accumulate. The quick-scan is based on only readily available data. The most important is an accurate DEM, which is freely available for the whole of the Netherlands (AHN2). With 9 points per square meter and a vertical accuracy of several centimeters this provides an insight in the surface elevation. Other data used are: GIS-maps with infrastructure and houses, the TOP10 (open data topographic data for the roads and waterways) and the BAG (open dataset with all buildings (2d) of the Netherland). Combining the elevation model, the dataset with buildings and aerial photographs a $3 \mathrm{~d}$ model of the city is constructed to get a better overview of the outcomes of the model.

The model was shown in the $3 \mathrm{D}$ virtual reality theater on a cylindrical screen using 6 HD projectors to project an image with a resolution of roughly $5000 \times 1800$. To display this model on a big screen a special 3D viewer was used, based on the open source OpenSceneGraph 3D toolkit. The software was running simultaneously on 7 PC's, one master PC for the control of the model and 6 slave PC's to drive the projectors. 
The resulting maps show the expected water depths for cloudbursts expected once per 100 years (for The Netherlands 60 in one hour).

For Ayutthaya (Thailand), the flood modelling work involved the use of onedimensional and two-dimensional (1D/2D) models. With such models, it was possible to explore the floodwater flows that are generated along roads, through fences and around buildings and to simulate and also optimize the consequent effects of any remedial works requirements [5-7]. The coupled $1 \mathrm{D} / 2 \mathrm{D}$ models are invaluable for this purpose. However, there is a great body of literature which suggests that great care is needed in the data collection and processing as well as the need to use an appropriate numerical modelling technique [8-16]. The DEM resolution used in the Ayutthaya work was $20 \times 20 \mathrm{~m}$. The model and maps produced were used for communication with local stakeholders and selection of remedial and flood protection works [3].

In Taiwan, the flooding information is achieved by the flooding potential map offered by the government. The map is based on the precipitation depth in various return periods, highlighting the potential flooding area based on a certain precipitation scenarios.

\subsection{Thermal stress maps}

Two types of models have been used to assess the thermal stress. A quick-scan GIS-based thermal stress map for large scale (city scale), and a prognostic model EVNI-met for small scale (city quarter).

The quick-scan GIS-based thermal stress maps have been developed in The Netherlands in order to give a quick insight in possible thermal stress locations in a city. It is based on accurate DEM and the assumption that for a quick insight of thermal stress some rough simplifications of the actual physical processes can be made. The maps give an estimate of the maximum PET (physiological equivalent temperature) during a heat wave. Such maps also have been made for Groningen and Bangkok [17].

ENVI-met software is typically used to accurately simulate the climate conditions in urban areas. The model had been adopted to conduct research in many of countries. It is much more elaborate than the GIS method and attempts to take into account all important processes. In this study, ENVI-met is used to make a thermal stress map for a part of the city centre of Groningen and a part of Tainan (Fig. 5).

The thermal maps for the Dutch and Asian cases are used to compare the differences in simulation results between different climates zones [16]. It gives insight in the differences in hot spot distribution and thermal stress levels between Taiwan, Thailand and the Netherlands. Next to this the comparison of the GIS tool and the ENVI-met tool is used investigate the limitations and advantages of the different tools.

\section{Results}

\subsection{Flood maps}

The flood map of Tainan was made for the scenario of a three days heavy rain of over 1200 $\mathrm{mm}$. The map shows that, the place with a lower elevation and a higher impervious pavement is vulnerable to flooding. However some places with low elevations but high pervious pavement ratios will be more safe when facing the flood related issues (e.g. parks and schools).

The flood map of Groningen shows inundated points in the center that are known to flood during heavy stormwater events with a maximum level about $50 \mathrm{~cm}$. Social media posts, photos and videos from citizens were gathered by researchers to verify these points 
(Fig. 2) and have been mapped on www.climatescan.nl [18]. Based on the insight in the vulnerable flooding spots (Fig. 3) the municipality has planned to implement some sustainable urban drainage systems (SUDS) to minimize these floods. The municipality is advised to reduce the vulnerability to flooding by reshaping some streets during reconstruction of the area. Those streets will be designed in such a way that they can convey the excess storm water without causing flood problems. The changes in Groningen and other cities as Amsterdam [4] will be carried out during a planned retrofitting of the urban spaces [16-17]. This way the roads themselves will act as a cost effective drainage system by discharging stormwater to the surface water bodies, preventing the flooding of houses. Similar plans have been developed using the results of the flood modelling in Ayutthaya (Fig. 4).

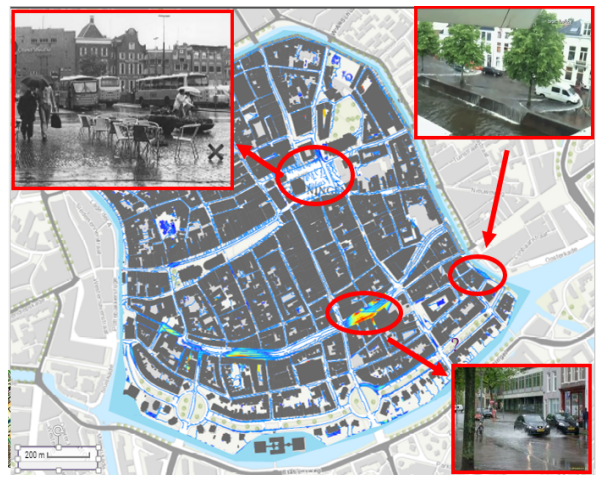

Fig. 2. Floodmap Groningen (The Netherlands)

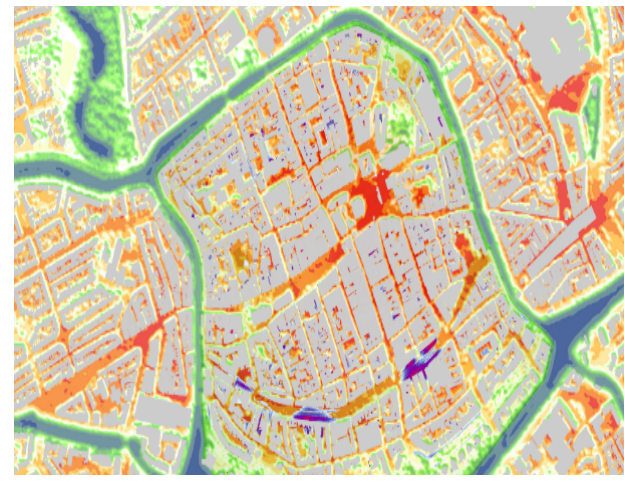

Fig. 3. Combined flood and heatstress map Groningen

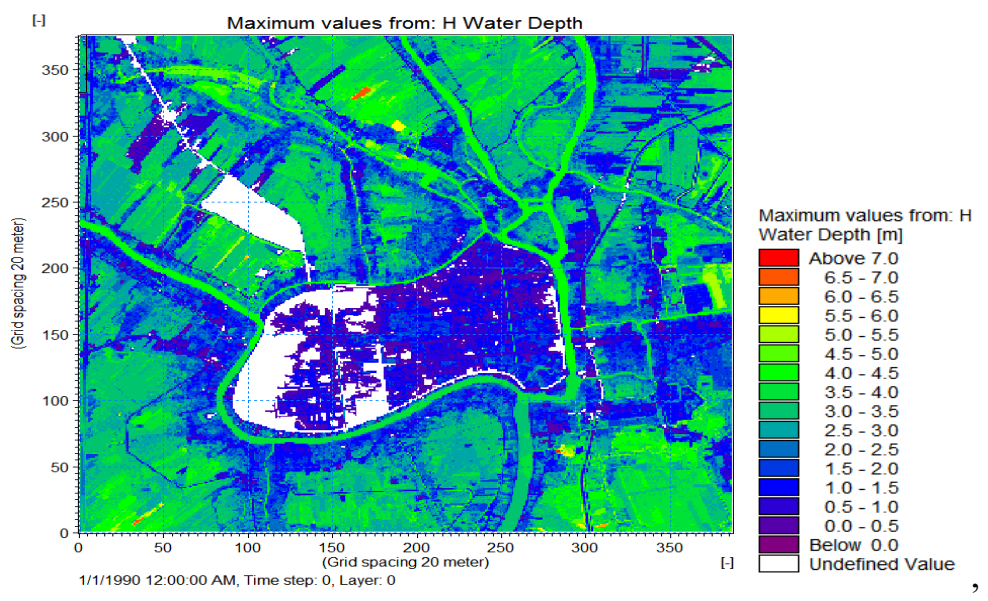

Fig. 4. Floodmap at Ayutthaya (Thailand)

\subsection{Thermal stress map}

Thermalhermal stress maps have been used to identify hot spots within the cities. PET is a indicator for thermal stress. PET-values in the hotter Asian cases are of course much higher than in the Dutch case due to higher air temperatures and radiation values [16]. The levels at which people perceive heat stress is also different. For The Netherlands there are no 
guidelines with maximum allowable PET-values. The maps are therefore mainly used to get attention for the issue of heat stress and to see the differences within the city.

The maps revealed that Tainan generally has high thermal stress (Fig. 5). Spaces with more greenery and pervious pavement like parks, have much lower thermal stress, than dense areas with high buildings and more impervious pavement, e.g. commercial districts show significantly more extreme thermal stress in summer time.

The thermal stress map of Groningen shows hotspots (Fig. 3 and 7) in the center where there is little green space or water bodies. The Noorderplantsoen, a park on the left top of figure 3, shows lower temperatures in the shades of the trees and near the water that flows through this green area. Climate measurements in these areas were taken at the same time as interviewing users of the public space. These results generally verified the quick-scan model results. An observation was that during the heat wave in the summer of 2015, inhabitants of the city avoided open paved shopping streets and marketplaces and instead retreated to the green park areas.

Although different models have been applied to predict the thermal stress in these three case studies, it is clear that the hot spots in most cases appear in the high density areas with impervious pavement, wheras the cool spots appear in the green areas and next to water bodies [16]. The comparative results demonstrate that the land use and land cover are highly related to thermal condition in the focus areas.

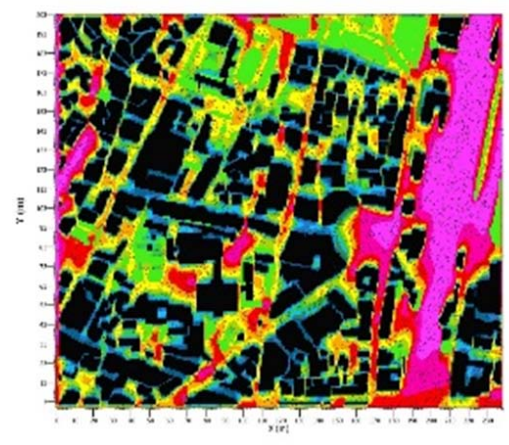

Fig. 5. Heatstress Tainan (Taiwan)

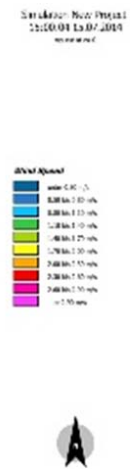

A.

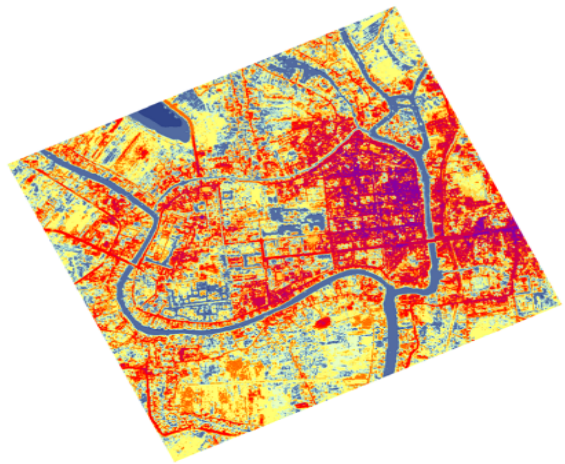

Fig. 6. Heat stress map in Ayutthaya

(Thailand)

\subsection{Combined approach for reduction of heat stress and flooding}

GIS maps for heat stress and urban flooding are easily combined into one map showing which urban locations are vulnerable to the effect of climate change (Fig. 3). Measures to prevent or reduce flooding and to reduce urban heat can often be combined and carried out at the same time. This is especially true if above ground solutions are chosen to reduce flooding. Solutions like providing more green spaces in general help to abate both flooding and heat stress, since they increase evaporation and provide place to temporarily store excess storm water. The models and literature show that trees are the most effective in reducing heat stress, mainly because they provide shade.

\subsection{3-D visualization}

Combining the elevation model, the dataset with buildings and aerial photographs a 3D model of the city is created to get an improved overview of the outcomes of the model. The 
model was shown in the $3 \mathrm{D}$ virtual reality theater on a cylindrical screen using $6 \mathrm{HD}$ projectors to project an image with a resolution of roughly 5000x1800. The software was running simultaneously on 7 PC's, one master PC for the control of the model and 6 slave PC's to drive the projectors [19]. After the flood modelling, the heat stress was visualized in 3D (Fig. 7). These visualisations and interactive communication tools can be used to encourage knowledge-sharing of climate-proofing and urban resilient projects [18].

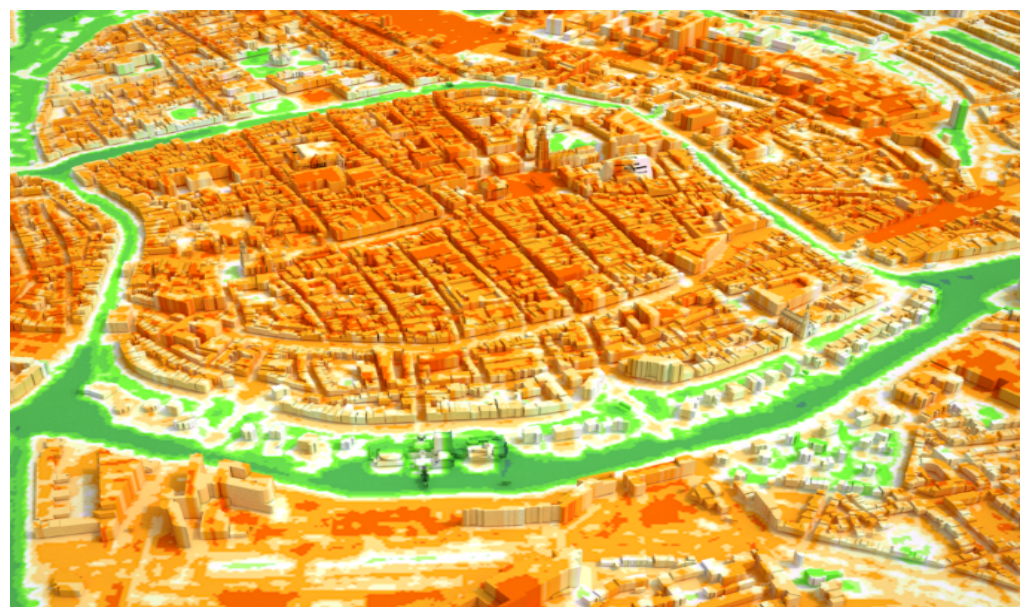

Fig. 7. Heatstress 3D after 3D floodmodel, Groningen (The Netherlands).

\section{Conclusions}

GIS maps for heat stress and urban flooding are easily combined into one map showing which urban locations are vulnerable to the effect of climate change. Measures to prevent flooding and to reduce urban heat can often be combined and carried out at the same time. These combined maps are ideal quick-scan tools for urban planners who need to make early decisions quickly. In the three cities of this study, such combined mapping tools have proven invaluable in the decision-making process and it is envisaged that they will have similar successes in other cities the world over.

In Groningen these maps have been an important input for masterclasses on climateadaptation in Groningen and other cities in the Netherlands. It raised awareness on the need to implement measures to tackle floodings and heatstress and has led to the implementation of various sustainable urban drainage systems. This experience will be applied in the other regions of the world as Thailand and Taiwan.

Challenges and further developments associated with combined thermal stress and floods and other climate related issues in dense urban areas are continuously growing. The datasets are getting bigger and stakeholders are becoming more demanding and require faster andmore visual results. The technology using DEMs (digital elevation maps) is becoming more common and improved, both with a higher accuracy and a higher resolution. The accurate comparison of the results of the different models is still to be carried out. This will highlight to what level a quick-scan mapping is sufficient and when a more accurate and detailed modelling is needed. The choice between coarse and a fine scale modelling will vary within each situation, depending on the needs. The more accurate and complete models lack the ability to perform on a large scale. This can be tackled by the use of high performance computing facilities and/or by running the model on high performance clusters. 
This study would not have been possible without the funding and collaboration within the projects climateproof cities (in Dutch: de klimaatbestendige stad), WaterCoG, INXCES, PEARL and the the long-term support we have received from the several stakeholders in the cities from The Netherlands, Thailand and Taiwan.

\section{References}

[1] J. Garssen, C. Harmsen and J. de Beer, The effect of the summer 2003 heat wave on mortality in the Netherlands. Eurosurveillance, 10(7), 165-168, (2005)

[2] Worldweather online, (2016), Retrived on September 20, 2016 from $\mathrm{http} / /$ www.worldweatheronline.com/bangkok-weather-averages/krung-thep/th.aspx

[3] Z. Vojinovic, D. Golub, M. Hammond, S. Hirunsalee, S. Weesakul, V. Meesuk, NP. Medina, M. Abbott, A. Sanchez, S. Kumara, 2015, Holistic approach to flood risk assessment in urban areas with cultural heritage: a practical application in Ayutthaya, Thailand, Natural Hazards, Springer, (2015)

[4] J. Kluck, F.C. Boogaard, D. Goedbloed, M. Claassen, Storm Water Flooding Amsterdam, from a quick Scan analyses to an action plan, International Waterweek 2015, Amsterdam, (2015)

[5] A. Mynett, and Z. Vojinovic, Hydroinformatics in multi-colours - part red: Urban Flood and Disaster Management, Journal of Hydroinformatics, 11(3-4), 166-180, (2009)

[6] W. Barreto, Z.Vojinovic, R.K. Price and D.P. Solomatine, A Multi-objective Evolutionary Approach for Rehabilitation of Urban Drainage Systems, J. of Water Resources Planning and Management, 136(5), 547-554, (2010)

[7] Z. Vojinovic, S. Sahlu, S. Seyoum, A. Sanchez, H. Matungulu, Z. Kapelan and D. Savic, Multi-objective rehabilitation of urban drainage systems under uncertainties, J. of Hydroinformatics, 16(5), 1044-1061, (2014)

[8] A.F. Abdullah, Z. Vojinovic, and R.K. Price, Improved Methodology for Processing Raw LIDAR Data to Support Urban Flood Modelling - Accounting for Elevated Roads and Bridges, J. of Hydroinformatics, 14(2), 253-269, (2011)

[9] A.F. Abdullah, Z. Vojinovic and R.K. Price, A Methodology for Processing Raw LIDAR Data to Support 1D/2D Urban Flood Modelling Framework, J. of Hydroinformatics, 14(1), 75-92, (2011)

[10]V. Meesuk, Z. Vojinovic, A. Mynett and A.F., Abdullah, Urban flood modelling combining top-view LiDAR data with ground-view SfM observations, Advances in Water Resources, 75, 105-117, (2015)

[11] Seyoum, S.D., Vojinovic, Z., Price, R.K., and Weesakul, S., Coupled 1d and noninertia $2 \mathrm{~d}$ flood inundation model for simulation of urban pluvial flooding, ASCE Journal of Hydraulic Engineering, ASCE, 138(1), 23-34 (2012)

[12]Z. Vojinovic, S. Seyoum, M.H. Salum, R.K. Price, A.F. Fikri, and Y. Abebe, Modelling floods in urban areas and representation of buildings with a method based on adjusted conveyance and storage characteristics, Journal of Hydroinformatics, 15(4), 1150-1168, (2012)

[13]Z. Vojinovic, and D. Tutulic, On the use of 1D and coupled 1D-2D approaches for assessment of flood damages in urban areas, Urban Water Journal, 6(3), 183-199, (2009) 
[14]Z. Vojinovic, S.D. Seyoum, J.M. Mwalwaka and R.K. Price, Effects of Model Schematization, Geometry and Parameter Values on Urban Flood Modelling, Water Science and Technology, 63(3), 462-467, (2011)

[15]D. S. Kumar, D.S. Arya and Z. Vojinovic, Modelling of urban growth dynamics and its impact on surface runoff characteristics, Computers, Environment and Urban Systems, September 2013, 41, 124-135, (2014). Disaster Risk Management - urban flooding, heatstress \& earthquakes [video]. Retrieved on September 20, 2016 from https:/www.youtube.com/watch?v=mzFahS9RJPA

[16]F, Boogaard, Y. Chen, J. Kluck, S. Yang, L. van der Meulen, T. Lin, The integration of storm water flooding and thermal stress potential in Tainan (Taiwan) and Groningen (The Netherlands), Lyon NOVATECH, (2016)

[17]J. Kluck, P. Bosch, B. Heusinkveld, P. van der Wal, Quick scan tool for heat stress:How to help the urban planner, poster ECCA Copenhagen, (2015)

[18]J. Tipping, F. Boogaard, R. Jaeger, A. Duffy, T. Klomp, M. Manenschijn, Climatescan.nl: the development of a web-based map application to encourage knowledge-sharing of climate-proofing and urban resilient projects, International waterweek 2015, Amsterdam, (2015)

[19]M. Verlaat, L. van der Meulen, G. Schoof, F. Boogaard, J. Kluck, Disaster Risk Management: Urban Flooding and heatstress, Geomatics Workbooks n ${ }^{\circ} 12$ - FOSS4G Europe Como 2015, (2015) 